\section{Commentary: Navigating between a rock and a hard place}

\author{
Sanford M. Zeigler, MD, ${ }^{a}$ and Arman Kilic, $\mathrm{MD}^{\mathrm{b}}$
}

The treatment of mitral valve disease in the setting of severe mitral annular calcification (MAC) is ripe for innovation. Not only are these operations technically demanding, with potentially fatal complications, but the patients are often high-risk surgical candidates due to advanced age and comorbidities. Technical issues encountered in MAC cases include an increased risk of paravalvular leaks, patientprosthesis mismatch, and atrioventricular groove disruption. Operating around severe MAC truly puts one between a rock and a hard place.

Surgical approaches to hostile mitral calcification are as varied as they are ingenious. ${ }^{1}$ On the spectrum are more conservative approaches that aim to gently debride the calcium enough to allow suture placement and a suitable size prothesis. Many surgeons favoring this approach use devices that can liquefy calcium to minimize risk of disruption with debridement. On the other end of the spectrum is aggressive debridement and removal of the calcification in its entirety, with patch reconstruction of the remaining defect. The latter technique is admittedly challenging from a technical perspective and is likely employed by greater-volume mitral surgeons, especially when considering that the average heart surgeon performs only 5 mitral operations per year. $^{2}$

The adaptation of transcatheter technologies for valve-inMAC procedures has begun prying the rock away from the hard place. These techniques allow such difficult cases to become safer, faster, and more reproducible. In this article, ${ }^{3}$

\footnotetext{
From the ${ }^{\mathrm{a} D i v i s i o n}$ of Cardiothoracic Surgery, Medical University of South Carolina, Charleston, SC; and ${ }^{b}$ Division of Cardiac Surgery, The University of Pittsburgh Medical Center, Pittsburgh, Pa.

Disclosures: Dr Kilic reported Medtronic (Advisory Board); Dr Zeigler reported no conflicts of interest.

The Journal policy requires editors and reviewers to disclose conflicts of interest and to decline handling or reviewing manuscripts for which they may have a conflict of interest. The editors and reviewers of this article have no conflicts of interest.

Received for publication Nov 13, 2020; revisions received Nov 13, 2020; accepted for publication Nov 13, 2020; available ahead of print Nov 19, 2020.

Address for reprints: Arman Kilic, MD, University of Pittsburgh Medical Center, 200 Lothrop St, Suite C-700, Pittsburgh, PA 15213 (E-mail: kilica2@upmc.edu).

JTCVS Techniques 2021;5:27-8

2666-2507

Copyright (C) 2020 The Authors. Published by Elsevier Inc. on behalf of The American Association for Thoracic Surgery. This is an open access article under the CC BY-NCND license (http://creativecommons.org/licenses/by-nc-nd/4.0/).

https://doi.org/10.1016/j.xjtc.2020.11.008
}

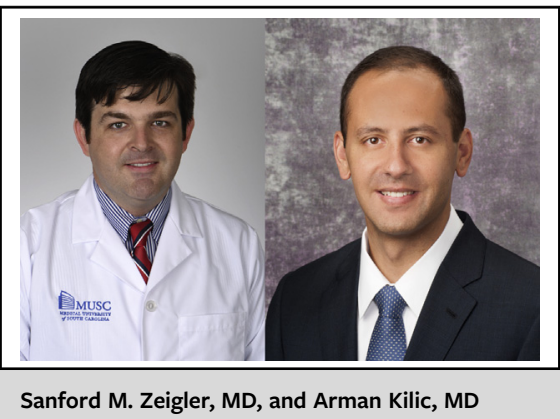

CENTRAL MESSAGE

Mitral valve procedures in the setting of severe mitral annular calcification are technically challenging but represent an opportunity for innovative approaches.

the authors demonstrated a few salient points about the nascent valve-in-MAC experience: (1) a bolstered skirt is needed to place a circular valve into the $\mathrm{D}$-shaped annulus; (2) the anterior leaflet needs to be moved away from the left ventricular outflow tract (LVOT); and (3) LVOT obstruction is only millimeters away.

The authors should be applauded for their ingenuity in dealing with point 1 . Other authors have sutured large felt buttresses into the mitral orifice or sutured pericardium to a balloon expandable prosthesis before loading it onto the catheter. ${ }^{4}$ To suture the skirt after deployment may allow for a slightly larger prosthesis and allows the skirt to be tailored in situ. This could lead to lower risk of stroke due to the decrease in foreign material in the left atrium and more laminar flow through the mitral prosthesis. Regarding point 3 , there is much work to be done to design a prosthesis or refine techniques to avoid LVOT obstruction. In the meantime, one should always be ready to deal with LVOT obstruction creatively.

While there is still no perfect solution for mitral valve surgery in the setting of severe MAC, technologies developed in the transcatheter space provide promising approaches to help obtain a reasonable outcome in this challenging patient cohort.

\section{References}

1. Bedeir K, Kaneko T, Aranki S. Current and evolving strategies in the management of severe mitral annular calcification. J Thorac Cardiovasc Surg. 2019;157: 555-66.

2. Bolling SF. Can we predict mitral valve repair rates by individual surgeons' mitral volume? Tex Heart Inst J. 2011;38:703-4. 
3. Codecasa R, De Cillis P, Stefano P. Balloon-expandable prosthesis for open mitral replacement with a calcified mitral annulus. J Thorac Cardiovasc Surg Tech. 2021;5:25-6.
4. Russell HM, Guerrero ME, Salinger MH, Manzuk MA, Pursnani AK, Wang D, et al. Open atrial transcatheter mitral valve replacement in patients with mitral annular calcification. J Am Coll Cardiol. 2018;72:1437-48. 